\title{
The application of clash-detection processes in building information modelling for rebars
}

Saminathan Chidambaram BE, MBA, PMP, IEng, MICE

BIM Manager, UK Infrastructure, Atkins, Bangalore, India

(saminathanc@hotmail.com)

\begin{abstract}
Building information modelling (BIM) is the key component in a digital revolution that is modernising the construction industry across the globe. This paper discusses the issues around rebar clashes in construction projects. Clash detection is an integral part of the BIM process. However, it is often overlooked in relation to reinforcing bars because this work often happens on-site. The underutilisation of a BIM-based rebar clash analysis can cause greater inefficiencies on the building site. The first part of this paper provides general information about these clashes and their categorisation and probable causes. The second part discusses the benefits of performing BIM-based clash detection on rebar. These benefits are evidenced by a practical example. The third part of this paper focuses on processing the clash-detection results to deliver BIM models without rebar clashes. This is achieved with a simple formula that has been adopted to quantify the efficiency of traditional and BIM-based clash-detection processes on rebar. Finally, the focus shifts onto how the results of these BIM model analysis can be communicated to the construction team for effective implementation at the project site.
\end{abstract}

\section{Notation}

C error coefficient

$C_{\mathrm{E}} \quad$ number of clashes found in the examined system

$C_{\mathrm{R}} \quad$ number of clashes found in the reference system

$P \quad$ performance coefficient

$P_{\mathrm{E}} \quad$ time necessary for detection of defined clashes in the examined system (s)

$P_{\mathrm{R}} \quad$ time necessary for detection of clashes in the reference system (s)

$P_{\mathrm{S}} \quad$ software performance coefficient

$T \quad$ preparation coefficient

$T_{\mathrm{E}} \quad$ time necessary for the preparation of the examined system (s)

$T_{\mathrm{R}} \quad$ time necessary for the preparation of the reference system (s)

$t_{\mathrm{c}} \quad$ time used for further clash analysis (result examination) (s)

$t_{\mathrm{d}} \quad$ time used for computational clash-detection analysis (s)

$\eta_{\mathrm{r}} \quad$ relative detection efficiency (\%)

\section{Introduction}

The construction industry is sometimes accused of being slow to embrace modern technologies and advancements of digital applications. This is cited as one of the reasons it has experienced a decline in labour productivity over the past three decades compared with other industries such as the automotive and finance sectors.

One of the key challenges in the construction industry is maximising the productivity of the teams involved. Poor communication and coordination can hinder the exchange of vital information between project stakeholders. Successful project execution requires phenomenal levels of coordination, collaboration and communication. Essentially, at critical points during the execution of a construction project, quality communication is required to ensure that the right information is shared with the right people at the appropriate time.
In addition, the construction industry is ripe for some level of innovative disruption. Large-scale projects across asset classes typically overrun by $20 \%$ of their planned schedule and can be up to $80 \%$ over budget. While the industry has been slow to embrace new processes and technological innovations, there is also a continuing challenge when it comes to fixing the basics (McKinsey, 2016).

The design stage of a construction project is of fundamental importance since it is where the majority of information is gathered and organised. The designs are shared with drafting or modelling teams to produce construction documentation such as drawings and models. Once the information is verified, it is shared as appropriate with the site teams in order to begin the preconstruction stage.

When using a traditional construction project planning process, two-dimensional (2D) drawings are shared with contractors once the design is finalised. After this, the actual construction process will start using the information available to the teams. However, designing is an iterative process and it can change due to unforeseen circumstances such as site conditions, space constraints and conflicts or complex layouts. This planning process relies on fundamentally inadequate information that could be greatly improved using an approach based on building information modelling (BIM).

The application of BIM is gaining popularity among construction firms. It is considered a very effective method of planning all construction projects since it adopts a data-centric approach. This enables plans to be checked for clashes, including rebar clashes, before any construction takes place, leading to fewer iterations throughout the construction process. The construction industry is now beginning to grasp the huge benefits of incorporating a BIMbased approach into all aspects of their planning activities. 
Using the latest BIM technology has a significant impact on design coordination by detecting design clashes before any construction has been undertaken. The management of rebar clashes on-site remains a real challenge for construction professionals, as it is labour intensive and time consuming due to the involvement of multidiscipline contractors. By using a BIM process, it is much easier to detect potential clashes between rebar and other aspects of construction such as architectural, service and embedment items. By identifying these issues in the early stages of planning, costly delays can be avoided further down the line.

The goal of this paper is to understand better and formalise the BIM-based clash-detection process for rebar. A practical example is presented to evidence the efficiency benefits of the BIM-based clash-detection process for rebar. Clashes are defined as conflicts that are detected through the automated clash-detection features of a BIM tool when two or more building elements occupy the same space (Eastman et al., 2011).

This study focuses on the comparison between traditional and BIM-based clash-detection processes of rebar in reinforced concrete buildings. The author intends to discuss the conceptual guidelines for the implementation of the BIM-based clashdetection process for rebar.

\section{Literature review}

\subsection{Building information modelling}

The US National Institute of Building Science (NIBS, 2019) committee defines BIM as 'a digital representation of physical and functional characteristics of a facility'. Thus, it serves as a valuable and reliable information resource on which to base decisions during the life cycle of the project from its inception to the demolition phase.

In simpler terms, BIM means building twice: first building virtually in a digital environment and then constructing the building in the real world. BIM technology has the potential to revolutionise the construction industry with its countless benefits, but it has yet to be utilised fully by them.

Using digital, BIM-based technology to design and plan construction projects will transform the way that people live, play and work. The appropriate use of BIM will make construction projects not only cheaper and more efficient but smarter too.

Using BIM gives construction companies the ability to visualise different project details within a realistic model. This also allows subcontractors to detect and resolve easily any potential clashes and other design faults flagged by the software during the planning and execution phase of the project (Cherkaoui, 2016).

The aim of BIM is also to provide electronically every piece of information about a facility in all stages of the project. If all project stakeholders implement BIM appropriately, it will improve the efficiency of the project by optimising the time and cost of construction (Figure 1).

A BIM object is a combination of many things (NBS, 2019):

- information content that defines a product

n product properties, such as thermal performance

n geometry representing the physical characteristics of the product

- visualisation data giving the object a recognisable appearance

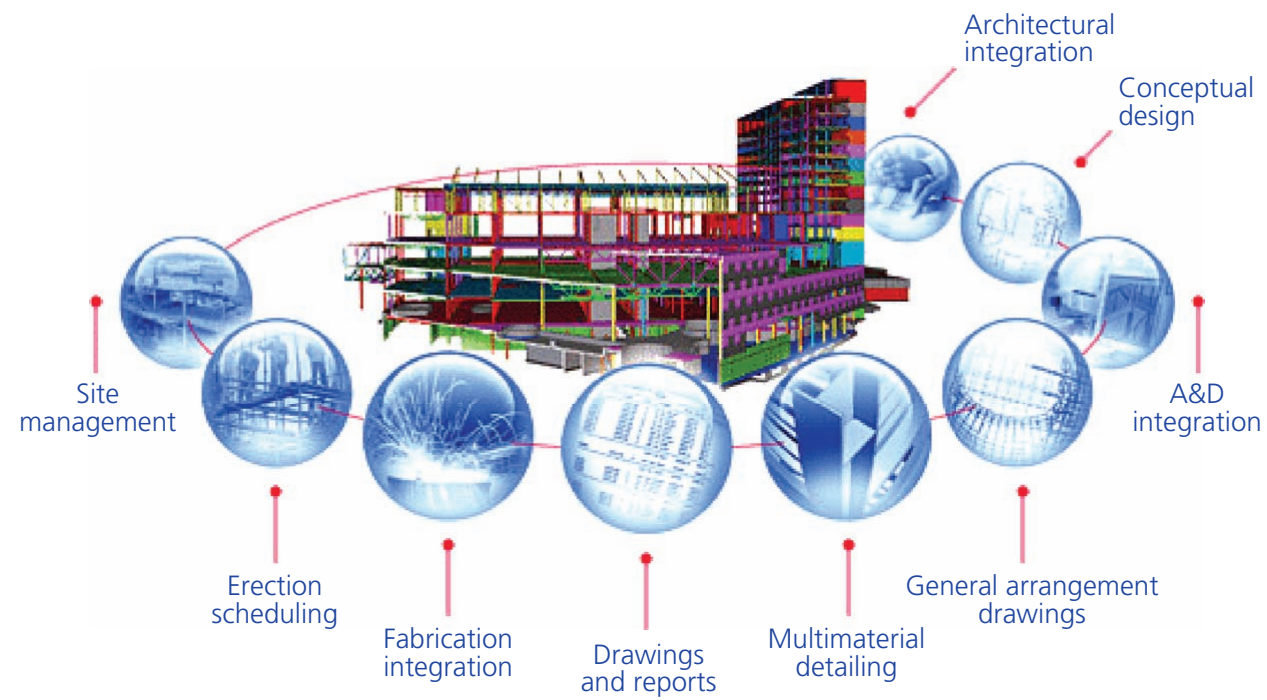

Figure 1. BIM workflow (source: Trimble). A\&D, analysis and design 
- functional data, such as detection zones that enable the object to be positioned and orchestrated in the same manner as the product itself.

BIM is a collaborative way of working where three-dimensional (3D) models are developed with the input of all project stakeholders, such as clients, contractors, engineers and fabricators, in the early stages of the project, allowing them to provide valuable input into the project.

Contractors can plan their methods of construction immediately after the design stage (i.e. during the modelling stage) and provide the results for use by the modelling team. Furthermore, the contractors can review the $3 \mathrm{D}$ models and provide more valuable feedback on the models to enhance buildability. Once the contractor has approved the final model, design construction can begin with confidence. This is known as an integrated project delivery approach since it involves a greater level of collaboration between designers, clients and contractors.

The idea behind BIM is that all the project stakeholders can create and share their information in a real-time, 3D space, making the process more robust and effective.

\subsection{BIIM for rebar}

Contractors and rebar manufacturers are less likely to adopt a BIM-based approach than other specialists, such as architects and engineers. BIM-based rebar modelling is often used in design for visualisation, documentation and checking adaptability of a design. However, the potentials of BIM for clash detection, code adoption, estimation, scheduling and project coordination have not been used extensively.

Reinforcing bars are an integral part of a reinforced concrete building, but it can be time consuming to use BIM technology to model rebar configurations in a $3 \mathrm{D}$ environment. However, with advancements in 3D BIM technologies, it is now becoming quicker and easier to design, model, document, track and control rebar. Utilising these 3D BIM technologies greatly improves the overall productivity and cost management for the entire project. Changes in rebar designs and placements can be instantly integrated into the 3D model, and plans can be modified accordingly. The design reports, drawings and schedules can be drawn up from 3D models far more efficiently than when using 2D designs. They are also more reliable and fully traceable for auditing (Figure 2).

One of the greatest benefits of 3D BIM modelling is the ability to share easily the designs between architects, structural engineers, contractors and fabricators. With a shared centralised model, all project stakeholders can access the latest reinforced concrete design, leading to improved precision and efficiency. All design disciplines such as mechanical, electrical and plumbing (MEP) engineering can access and integrate the most up-to-date design information into their work schedules and plans. It also allows

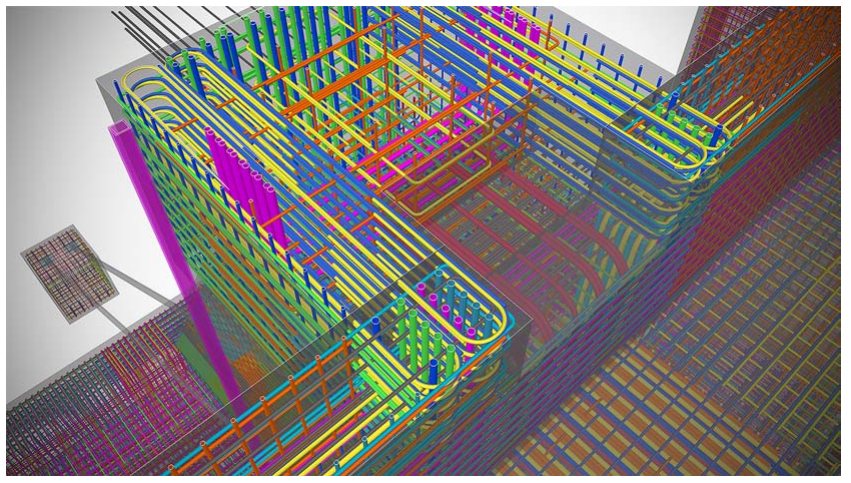

Figure 2. BIM rebar model (source: Trimble)

any design clashes to be predicted and resolved before they are encountered on-site (Allplan, 2018) (Figure 3).

The use of 3D BIM modelling for rebar can be a powerful validation tool for the design and buildability of reinforced concrete buildings. This approach helps identify, check and solve any rebar clashes to avoid expensive buildability issues during the construction process.

\subsection{BIM tools}

BIM tools provide a model-based process for generating a digital representation of the physical and functional characteristics of a facility for designing and managing construction projects. There is a wide range of BIM tools available today in the market. However, it can be challenging to choose from the long list of available BIM tools. They also improve designs between all project stakeholders, since 3D models are easier to understand and interpret than 2D designs. BIM tools are primarily for generating design information in a 3D space and storing, managing and retrieving the information. Multi-user functionality is one of the key features of BIM tools that allow multiple users to work concurrently on the same model. Most BIM tools come with a respectable list of features, but every software package will have slightly different functionalities and features.

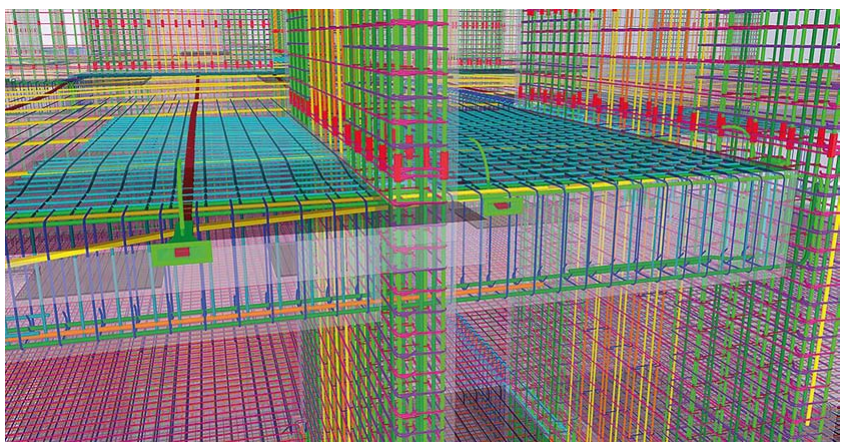

Figure 3. Highly coordinated BIM model (source: Trimble) 
The choice of BIM software is a crucial factor in an organisation's competitiveness. Whether the organisation is transitioning from $2 \mathrm{D}$ to $3 \mathrm{D} / \mathrm{BIM}$ or replacing existing software, the choice of BIM software has far-reaching consequences on the organisation's processes, projects and success. Every company has individual requirements, and each software has its own strengths and weaknesses. It is important to evaluate and assess which is the best-suited BIM software based on the requirements. However, several common criteria should be considered when choosing BIM software, and there are questions that each provider should answer (Trimble Solutions (UK) Ltd, 2020).

The summarised checklist for selecting BIM software can be found in the following. The software should be as follows:

- Open. Open BIM software promotes the free exchange of models between different software packages and supports open exchange formats, such as the Industry Foundation Classes (IFC) format developed by the buildingSMART association.

- Model smart. BIM software should be easy to model and flexible enough to make changes easily. BIM software packages are based on so-called parametric modelling. The individual parts or components of the building model are related to each other and influence each other. Each part is assigned parametric properties, such as height, length, width and position. If one part changes, the parts related to it also adapt automatically.

- Powerful. In a BIM project, 3D modelling is always enriched with information. Considerable amounts of data are used to make this happen. BIM software should, therefore, be able to handle the data workload comfortably and remain powerful and agile even on larger projects.

- Licensed, maintained and supported. The licensing and maintenance terms of BIM software determine how and when it can be used and how often it is updated to ensure that it remains secure and stable. Therefore, the implications of licensing, maintenance and support plans must be carefully considered.

- Cost effective. New software often means making a significant investment in both time and (particularly) money. One should, therefore, undertake a cost-benefit comparison: comparing the cost of purchase, training (including downtime) and maintenance with the expected benefits. The solution that initially looks cheap does not always offer the most costeffective solution in the long term.

- Planned for the future. The choice of BIM solution should best fit both project and organisational needs. At the same time, it is also an investment in the future. The construction industry is changing, rapidly driven in part by digital construction. Businesses will face new expectations and demands on how to handle projects efficiently. The decision should, therefore, include not only the current business situation but also possible future developments.

The information in a BIM model is shared through a mutually accessible online space known as a common data environment
(CDE), and the data collected are referred to as an 'information model'. Information models can be used at all stages of the life of a building: from inception to operation and even renovations and renewals.

\subsubsection{BIM authoring tools}

BIM authoring tools are used to develop BIM models based on the design information provided and allow the user to generate data for multiple uses. These tools are commonly used between the design phase and the construction documents phase (BIM@SG, 2012).

\subsubsection{BIM analysis tools}

BIM analysis tools are used to analyse and predict model behaviour. They are used to validate model compliance with standards/codes and allow users to carry out engineering analyses. These tools are commonly used in the preliminary design phase until the construction phase (BIM@SG, 2012).

\subsubsection{BIM collaboration tools}

BIM collaboration tools are used for combining or federating different discipline models to see how they will interact with each other in the real world. They can be used to identify potential problems in the coordination between different models and allow users to provide comments and mark-ups to overcome any issues. These tools are commonly used in the design phase for quality assurance and discussion of solutions to any arising issues during collaboration meetings.

\subsection{Types of clashes and their causes \\ 2.4.1 Types of clashes}

In the BIM literature, a clash is defined as two or more objects occupying the same physical space (Benning et al., 2010). In the context of BIM, a clash is the penetration of two or more objects in the model. Generally, clashes are often categorised into (Figure 4):

nard clashes

- soft clashes

- clearance clashes

- duplicate clashes

animated clashes.

\subsubsection{HARD CLASHES}

A hard clash represents two or more objects occupying the same physical space or two objects intersecting each other. It usually involves geometric issues only, making these clashes easy to recognise. Hard clashes are considered potentially dangerous and must be resolved as soon as possible.

\subsubsection{SOFT CLASHES}

A soft clash represents an object that can hinder the movement of other objects or clashes that occur when objects need more spatial or geometric tolerances within required limits due to movement, space, installation, manipulation and connection requirements. It highlights the clashes between the objects and the buffer zone 
Smart Infrastructure and Construction

Volume 172 Issue 2
The application of clash-detection processes in building information modelling for rebars

Chidambaram
Rbr-Rbr (hard)
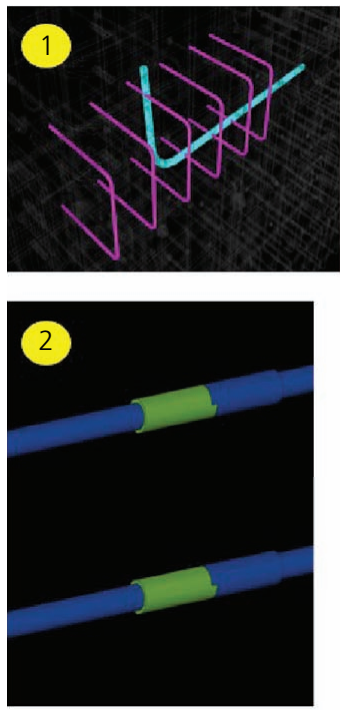

Cplr-Cplr (hard)
Cplr-Rbr (hard)
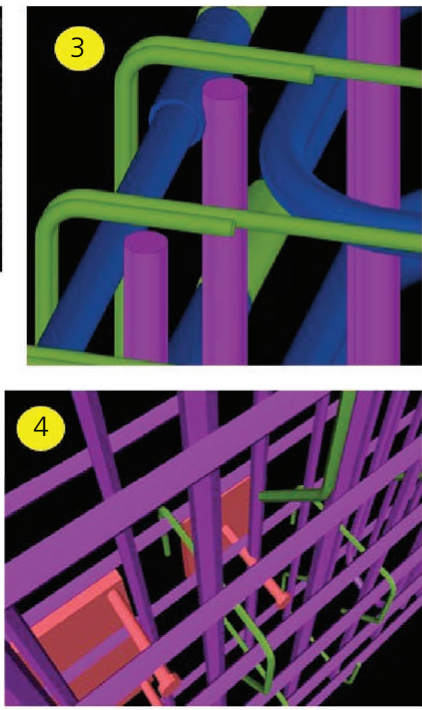

Ebd-Rbr (hard)
Ebd-Rbr (soft)
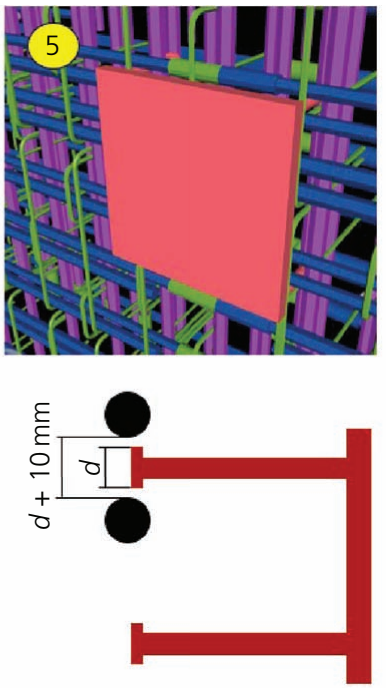

Anchor plate between reinforcements
MEP-Rbr (clearance)
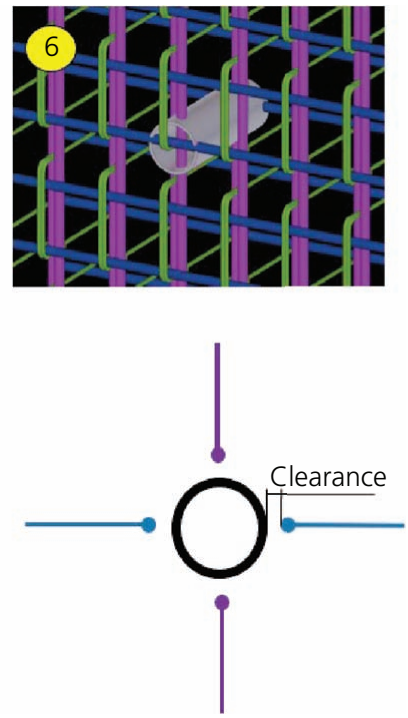

Reinforcement around sleeve

Figure 4. Types of clashes (snapshot is taken from an example of a Tekla model). CPIr, coupler; Ebd, embedment; MEP, mechanical, electrical and plumbing; Rbr, rebar

created around other objects. The soft clash is also known as the conservative hard clash.

\subsubsection{CLEARANCE CLASHES}

A clearance clash represents conflicts that occur between objects and clearances. This is specified by the building code, regulation or clash, and when they occur, they are treated as intersecting if they do not maintain specified clearance.

Clearance clashes can be predicted easily through the creation of certain rules. It should also be noted that some of these clashes can be ignored if they are not critical design errors and can be managed at the site easily. A clearance clash is also known as a near-miss clash.

\subsubsection{DUPLICATE CLASHES}

A duplicate clash indicates that two or more intersecting objects are identical in type and position within a tolerance range. While modelling, the modeller creates at least two objects in the same location, usually due to accidentally copying the original object.

It is easy to detect these clashes in the model, and they mainly affect the quantities in the bill of materials or bar bending schedules.

\subsubsection{ANIMATED CLASHES}

An animated clash represents two or more objects intersecting each other due to their dynamic characteristics, but they need not clash when they are in a static position. This type of clash can be found by performing virtual sequencing, but this is quite time consuming.
Performing an animated clash analysis on rebar is useful, as the contractor can perform virtual sequencing to find which bars are not buildable. It is very similar to a soft clash, but here it checks the clashes between the object and dynamic buffer zone of other objects (Matejka and Sabart, 2018).

\subsubsection{Causes of clashes}

It is fundamental to understand the various reasons why clashes occur so that they are eliminated before construction begins rather than just detected and dismissed. Clashes in reinforcement steel are inevitable because they are required by construction codes and standards.

The most common causes of hard and soft geometric clashes in a BIM model are summarised as follows (Anderson and Zulfikar, 2017):

- use of wrong or insufficient levels of detail

- design uncertainty/use of placeholders

- failure to adhere to design rules

- accuracy against deadline

- 3D model objects exceeding the required clearance

- designers working in isolation from each other

- design complexity

- insufficient timing

- use of 2D instead of 3D models

- design errors

use of different file formats

- lack of expertise. 
Designers from different disciplines working in isolation from each other and unbuildable designs can also cause reinforcement clashes. They can be easily mitigated by collaborating early with contractors to ensure that they understand the reinforcement and concrete methods before construction with the use of BIM models.

\subsection{Clash detection and its methods}

\subsubsection{Clash detection}

Clash detection is an iterative process in which all noted project conflicts are addressed and re-evaluated until the desired level of coordination has been achieved (Ghanem and Wilson, 2011).

Clash detection is the process of inspecting and identifying conflicts within different BIM models for the purpose of smooth coordination. Clash detection is sometimes referred to as collision detection or coordination.

This process affects major decisions within the design processes and, if properly utilised, can facilitate a smooth construction execution. Clashes can occur at different stages of the project. They are best resolved in the earliest stages of the project when it is most economical.

\subsubsection{Clash detection in non-BIM-based environments}

Clash detection can be carried out using 2D drawings by superimposing or overlaying multidisciplinary 2D drawings with transparencies and manually identifying the potential clashes within or between different discipline drawings through visual inspection.

Clash detection with 2D drawings is difficult, and it takes a lot of time to spot all of the clashes since disparate pieces of information are available from different disciplines and integrating them into the project could create a whole lot of stress.

In a $2 \mathrm{D}$ environment, the accuracy of clash-check results depends on the experience and visual ability of the draftsman. If there are any changes in the inputs, the whole visual inspection process has to be restarted from the beginning. The biggest problem with $2 \mathrm{D}$ clash detections is that there is a high chance of human errors in the visual inspection results.

\subsubsection{Clash detection in a BIM-based environment}

BIM applications can spot the clashes within the model automatically with the click of a button. Whenever there are changes in the model, all the user needs to do is rerun the clash check to obtain the revised results. All the clash-check results are free from human miscalculation or misinterpretation errors.

Clash checks can be done on models that have been created in different (compatible) BIM applications, within models or between different models. This flexibility allows different disciplines to use 3D BIM models to eliminate or resolve potential conflicts before actual construction begins.
Clash checks optimise construction processes and minimise the project cost by avoiding extra labour and material costs due to order changes. BIM-based tools allow clash detection to be combined with logic and rule-based clash analysis to identify structural clashes. It allows the user to check clashes selectively between a specific system and subsets and then flag them on the screen in vibrant colours to identify the exact location of clashes (Veillette, 2016).

One of the key benefits of BIM is the ability to spot clashes at an early stage in the project to avoid coordination issues between different discipline objects. It provides useful information on how data from different disciplines get along with each other and areas that need improvement.

Similarly, clash checks can be performed at any stage of the design process and among any number of building systems. The design team can also evaluate the design decisions that are critical to the project and work collaboratively to resolve them with logical, fact-based discussions.

Clash-detection processes run on rule-based or geometry-based algorithms to inspect and identify the potential clashes in the model. This is one of the important quality assurance checks to be performed on all the BIM models since it maintains the integrity and quality of the model by identifying underlying modelling errors.

Clash detection can be performed by defining the rules and identifying the areas/elements that are not complying with the preset rules by the model. This method is useful when highlighting soft clashes, clearance clashes and animated clashes. Solibri Checker is a software program that works using this approach, and it can predict code violations.

Mostly, clash checks are performed by considering the geometry of the elements where they highlight the clashes where there are intersections between the elements. This method is useful in discovering hard clashes and duplicates. Tekla Structures, Tekla BIMsight, Trimble Connect, BIMcollab and Navisworks Manage are just some of the software applications that use this methodology to detect clashes (Figure 5).

Clash detection can be performed in BIM authoring software or BIM integration software. It would be advantageous to perform clash checks in BIM integration software since it has the flexibility to import BIM models from any BIM authoring software using an open BIM approach.

\section{Methodology}

\subsection{Clash detection for rebar}

Reinforced concrete construction would not be 'reinforced' if it did not have reinforcing bars. Reinforcing bars are often overlooked in the clash-checking process for various reasons. For 
Smart Infrastructure and Construction Volume 172 Issue 2
The application of clash-detection processes in building information modelling for rebars

Chidambaram

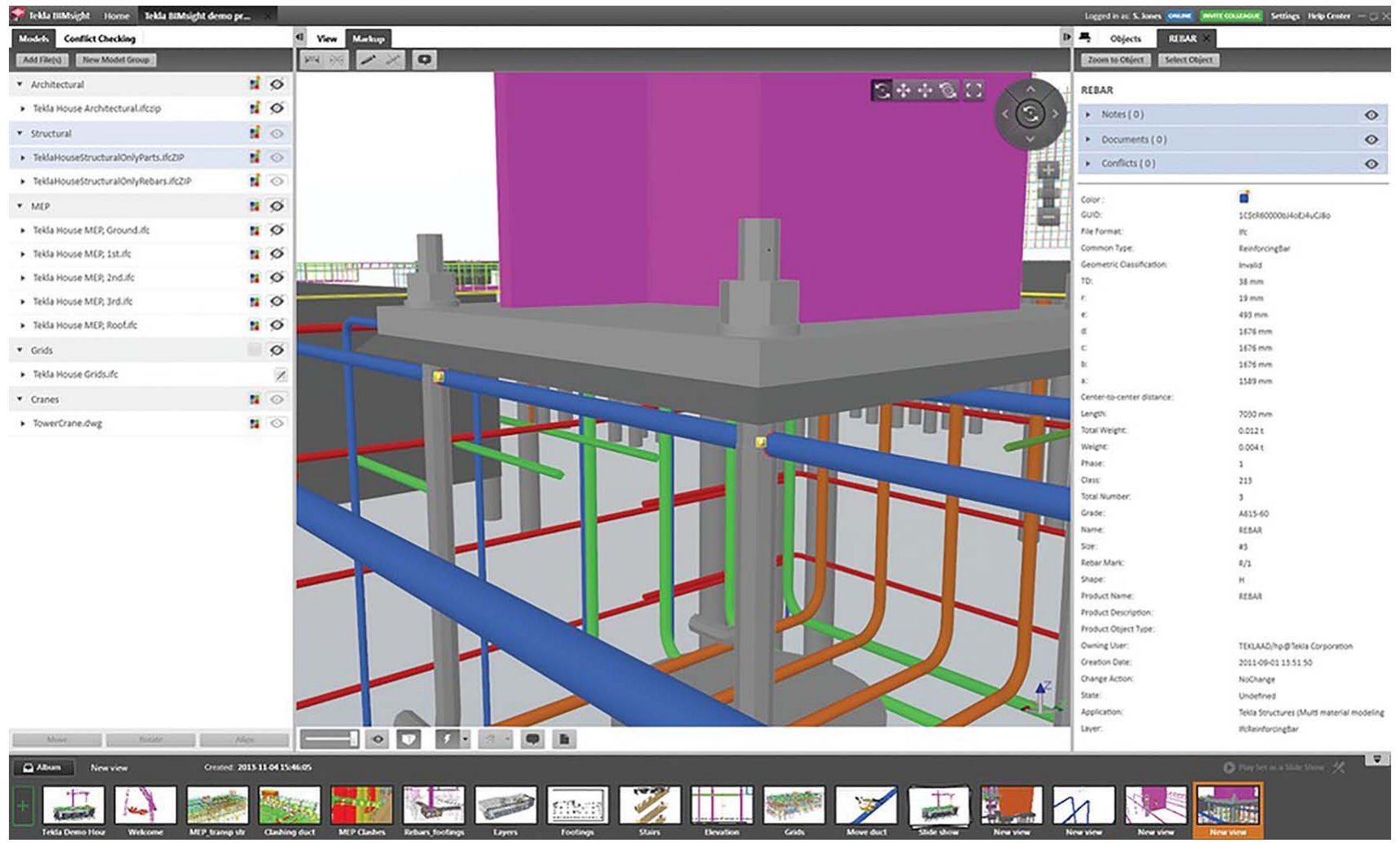

Figure 5. Rebar clash in Tekla BIMsight (source: Trimble)

simple structures, it is possible to overcome rebar clashes during the construction process due to their simple arrangement. It is usually only possible to overcome rebar clashes at the site if the bars are fixed in situ.

Inappropriate solutions implemented on-site can create some serious issues, including exceeding the maximum spacing, reducing lever arm stress and the incorrect covering of rebar that could affect the levels of resistance and durability of the structure. It is important to use a BIM rebar model with all major clashes removed and minor clashes identified and communicated with all project stakeholders.

Reinforced concrete constructions are commonly used as a costeffective building methodology. However, it is considered a labour-intensive method of construction in comparison with more sophisticated forms of construction.

Steel fixing is a labour-intensive process, but it offers considerable strength improvement when used in combination with reinforced concrete construction. However, productivity lessens as more steel is introduced into the construction process, particularly in complex or confined spaces, such as stairs and complex transfer beams.

In undertaking work in these situations, one has to understand that greater dexterity is required in tying the steel; greater mental attention is required to set out bars; greater care is required in checking for concrete cover; greater forethought is required for selecting the correct pieces from the stack; greater time is required in threading long or bent pieces into position; and there is a greater likelihood of the need to cut, bend and modify steel due to clashes from cluttered steelwork (Forsythe, 2014).

The steel fixer is the contractor who specialises in cutting and bending the steel reinforcement bars into the appropriate shape and fixing them into place following the project specifications. This is a labour-intensive and time-consuming task. The cost of rebar work makes up approximately $30 \%$ of the overall costs of reinforced concrete frames with $30 \%$ of these costs being labour. Fixing rebar into places is particularly labour intensive because of the confined space of the formwork moulds in which the reinforcement is fixed and the variability of rebar diameters, locations and details (Illingworth, 2000).

The penetration between the rebar is considered a clash and it is denoted as ' $p$ '. When the penetration is greater than the tolerance value, then it would be considered a clash. The tolerance limit ' $i$ ' is generally set to $3 \mathrm{~mm}$ for reinforcing bars with a nominal diameter strictly above $10 \mathrm{~mm}$ (Figure 6).

However, it would be a mammoth task for heavily reinforced structures to be de-clashed on-site. Anchor plates and anchor 
Smart Infrastructure and Construction

Volume 172 Issue 2
The application of clash-detection processes in building information modelling for rebars

Chidambaram

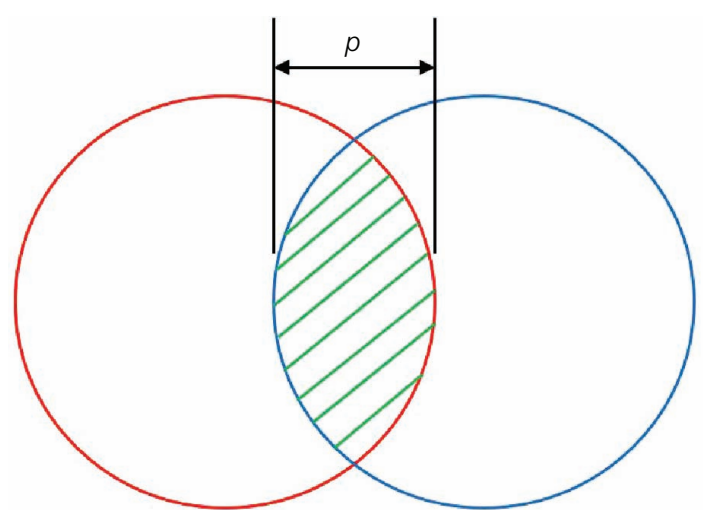

Figure 6. Illustration of a clash between reinforcing bars (devised by the author based on the literature)

channels that support other services make the de-clashing activity of rebar difficult since the embedded items cannot be moved out of the tolerance zone. Hence, the rebar needs to be de-clashed to get to the space for installing embedded items during the modelling stage.

\subsection{New workflow for BIM-based clash detection for rebar}

This study presents a new workflow for detecting the clashes of rebar in a BIM environment during the early stages of the project that can be applied to other projects to reproduce the results. In this study, BIM modelling for rebar refers to the modelling of reinforcing bars in a $3 \mathrm{D}$ environment that includes detailed lap design, rebar type, grade, quantity, spacing and location.

The requirements and specifications of this new workflow are established based on intense literature review and the application of the key learnings of the author. Afterwards, the 3D BIM model development and clash-detection process are carried out as part of the new workflow, involving many important phases right from the

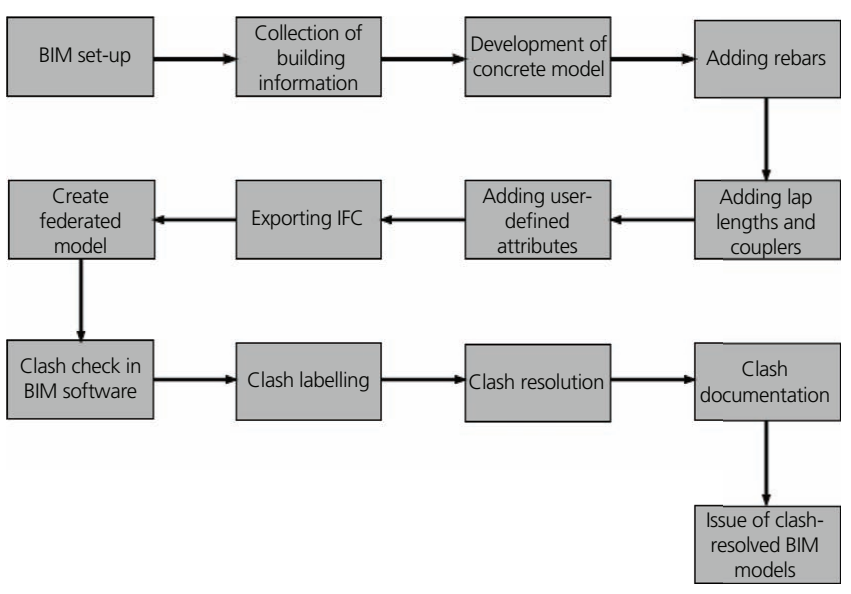

Figure 7. New workflow for BIM-based clash detection for rebar (devised by the author based on the literature and project experience) development of a concrete model to producing clash documentation. Figure 7 shows a flowchart of building a 3D BIM model with rebar and the clash-detection process in a 3D environment.

\subsubsection{Developing a concrete model}

The concrete model can be created using tools available in BIM authoring software with input data such as element name, size, shape, material and grade, position, levels and user-defined attributes (e.g. zone, core, phase and lot). BIM software supports import of 2D drawings through multiple file formats such as DWG and PDF, and they can be used as references to develop a concrete model. In BIM software, concrete elements can be easily modelled by selecting the points in the $3 \mathrm{D}$ environment that can define

- insertion points for columns and isolated footings

- lengths for beams, walls and strip footings

- shapes for all slabs (Figure 8).

It is assumed that the concrete model has been developed in BIM authoring software 1 and it needs to be used in BIM authoring software 2 where the reinforcing bars are going to be modelled. In this case, the concrete model can be exported from BIM authoring software 1 in IFC format and can then be imported into BIM authoring software 2. Most BIM authoring software programs can convert IFC files from other software programs to native objects by using a mapping system. It works well for regular geometry to convert IFC reference objects into native objects. However, due to limitations in this functionality, it does not provide the desired results when converting IFC files containing irregular geometry, skewed objects and objects in slope. After conversion, the converted concrete model needs to be checked against the reference model in the BIM authoring software to validate the conversion results. Conversion logs are also exported documenting how many objects were successfully converted and how many objects failed to be converted, making it easier to check the effectiveness of the conversion.

During the development of the concrete model, it is vital to add the rebar into the 3D environment and to prepare general arrangement drawings or concrete outlines of reinforced concrete (RC) detail drawings.

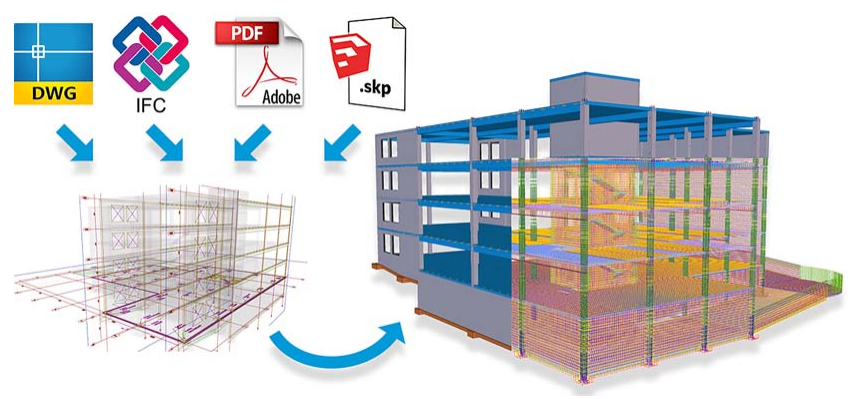

Figure 8. Inputs for developing a concrete model (source: Trimble) 


\subsubsection{Adding rebar}

The rebar can be modelled in the BIM authoring software by creating single rebar or rebar groups. The inputs required to create the reinforcement in BIM authoring software are as follows:

- bar name (e.g. B1, B1-U, B1-1 and B1-CPLR)

- bar grade/type and size (e.g. C20, B25 and H16)

- bending radius (automatically gets bending radius after selecting the type and grade based on codes and standards)

- on-plane cover (rebar cover values concerning the sides, top and bottom edge of the concrete)

v from-plane cover (start and end of the range/group from the edge of the concrete)

- spacing (centre-to-centre distance between rebar; multiple options are available)

- group type (normal/rectangle, linear taper, varying taper and spiral)

nar shape and leg dimensions (user input through the selection of points in the concrete model).

After creation, the rebar can be attached to the concrete element using the BIM software and the adaptability options can be set. When this is set up, the rebar would react to the changes in the concrete element. This is referred to as 'parametric modelling'.

\subsubsection{Adding lap lengths and couplers}

A very important step in BIM modelling for rebar is adding the laps and couplers. The lap lengths or couplers are modelled in the 3D environment to maintain the continuity of bars and safely transfer the load from one bar to another bar. It depends on numerous factors such as the grade of concrete, the grade of steel and the diameter of the rebar. It is particularly useful when the bar does not meet the required design length. In simple terms, lapping is using two bars side by side to achieve the required design length. Using couplers (also known as mechanical splices) achieves the same results as lapping and is preferable because it minimises steel congestion (Figure 9).

There are different types of couplers available, such as female, male, positional, bridging and transitional couplers and end anchors. Based on the project requirements, lap lengths and couplers can be modelled using BIM tools within the BIM authoring software. The connections should be placed, whenever possible, away from positions of high stress and should preferably be staggered. There are tools available in the BIM software to model lap lengths and couplers in a $3 \mathrm{D}$ environment. The inputs required to model lap lengths are the selection of rebar to be lapped, lap length, preferred side and position and percentage of bars lapped at the selected section. The inputs required to model couplers are the selection of rebar to be coupled, the leg that needs the coupler, coupler type and coupler make (Figure 10).

\subsubsection{Adding user-defined attributes}

User-defined attributes can be added for rebar such as planned start date, planned end date, actual start date and actual end date for

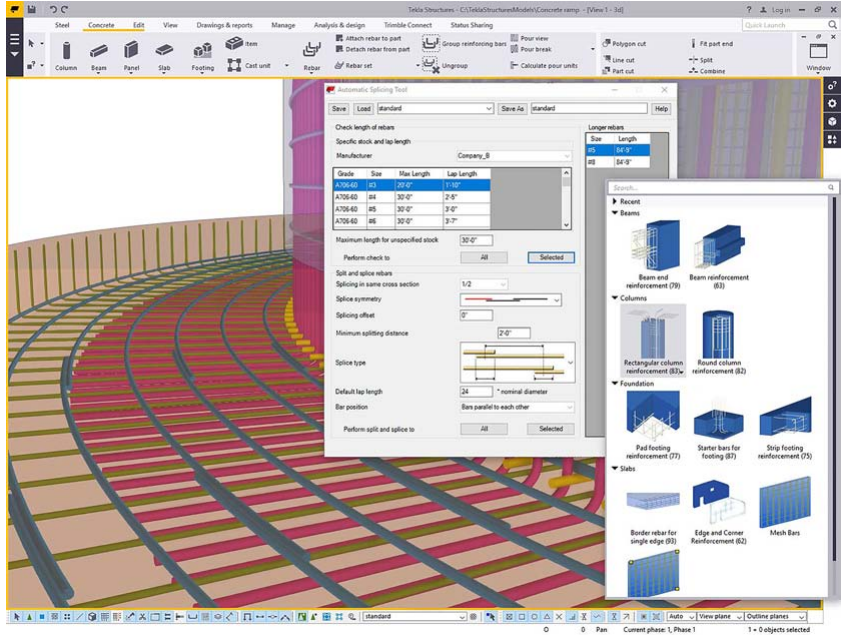

Figure 9. Adding lap lengths for rebar in BIM software (source: Trimble)

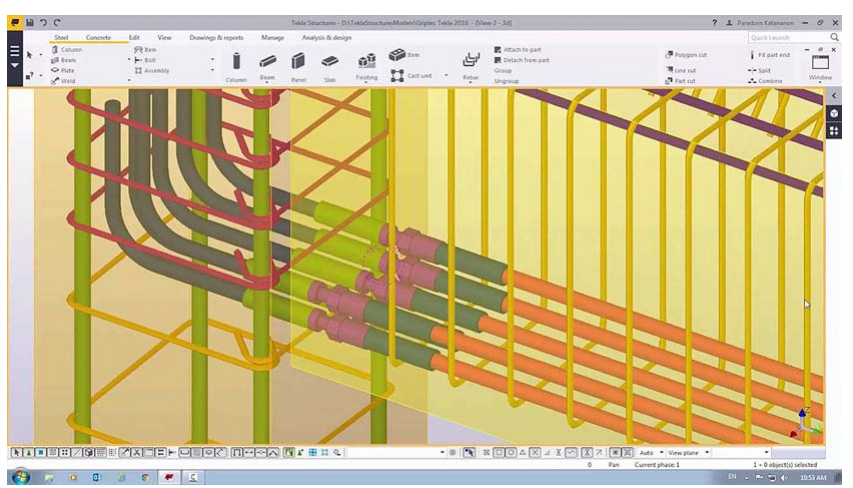

Figure 10. Adding couplers for rebar in BIM software (source: Trimble)

designing, modelling, fabricating and erection. The methods of reinforcement can also be provided as user-defined attributes such as in situ, prefabricated cages and meshes. Also, any information related to rebar that is useful for the construction team can be provided, such as drawing and material list references and status and revision of the model. The user-defined attributes can be assigned to the bars manually or automatically through the 'import attributes' option in the BIM software based on the unique properties of each rebar.

\subsubsection{Exporting IFC}

Industry Foundation Classes files, abbreviated as IFC files, are open format files supported by many BIM software applications. It is an object-based file format with a data model developed by buildingSMART, and it is a commonly used collaboration format in BIM-based projects. The concrete and rebar can be exported in IFC format based on the selection of objects and chosen export settings. The export settings are highly customisable, which allows the user to select the required geometry and data to carry out the quality assurance process in BIM collaboration/integration 
software or to use the intelligent 3D BIM models with reinforcing bars in downstream processes.

\subsubsection{Creating a federated model}

Collaboration is the key to the success of any construction project. BIM allows users to create a federated model by combining BIM models with input from mechanical, electrical, plumbing, architectural, structural and other disciplines. Each contractor will upload their contribution into a shared data environment known as the CDE where they can be accessed, edited and combined. This integrated approach allows stakeholders to use a shared model and ensures that they are all using real-time information (Figure 11).

It should be noted that the federated model can be used by all disciplines for data sharing and interoperability (Nour and Beucke, 2010). It is essential to have a combined or federated model of all disciplines to run the clashes in BIM software and find the clashes between rebar and other discipline objects.

\subsubsection{Clash checks using BIM software}

Once the IFC models from different disciplines have been imported into the BIM collaboration/integration software, different clash tests can be created by using a selection of objects, clash rules, clash types and clash tolerances. The selection of objects can be performed by defining rules to select objects based on their properties. The clash rules will allow the software programme to consider or ignore the clashes between items in the same layer, group or file. The clash rules can also be customised based on the clash matrix to suit the project requirements. The clash-detection process in BIM software provides clash results based on the clash type. The user can set the tolerance to ignore negligible clashes (that can be solved on-site) or set the clearance. A comprehensive understanding of the inputs required by the clash-detection process in BIM would help optimise the clashdetection results. The clash-detection process in BIM programs can be performed using either a geometry-based or a rule-based algorithm.

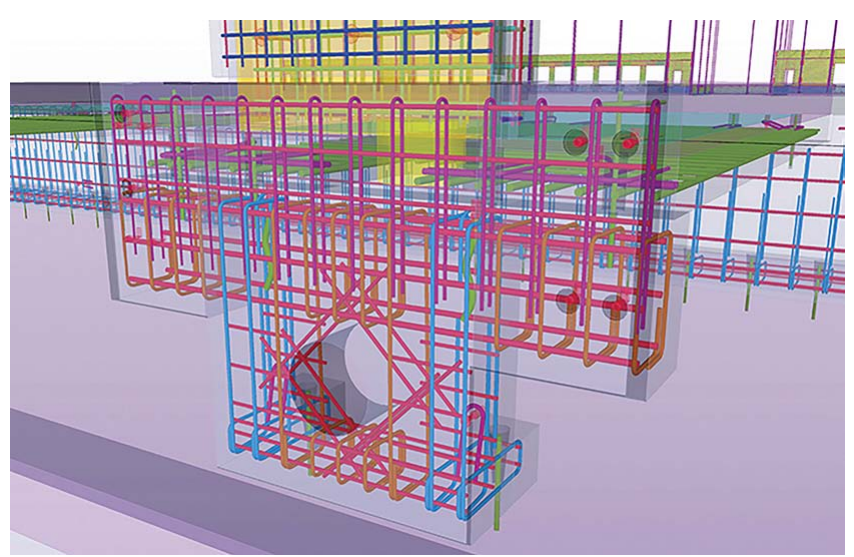

Figure 11. Federated BIM model (source: Trimble)

\subsubsection{Clash labelling}

After receiving the Hypertext Markup Language (HTML)-based clash-detection report, it needs to be converted into a spreadsheet for subject matter experts to label the clashes. The spreadsheet should contain columns with clash labels, each with a drop-down list containing four options: serious clashes or errors, negligible or pseudo clashes, legal interventions or deliberate clashes and unknown (Lin and Huang, 2019). The grouping of clashes is an important feature in BIM software to enable clashes to be grouped based on their nature. Some clashes can be safely ignored by the teams, and they can be grouped and shared with all project stakeholders before authorising the model for pre-construction activities.

\subsubsection{Clash resolution}

There are numerous options of resolving rebar clashes, including:

- adjusting the position of rebar

- adjusting the length of rebar

- adjusting the spacing of rebar

- changing the shape code of rebar

v cutting or trimming of rebar

adjusting the position of other discipline objects.

Project stakeholders must organise and conduct regular collaboration meetings to review, discuss and develop solutions and resolve the identified coordination issues or clashes between different discipline issues. The participants of the collaboration meeting would discuss the design information discrepancies and use their knowledge and understanding of the subject to provide optimal recommendations and solutions. Three-dimensional models would be used in the collaboration meetings to explain the various design coordination issues and their proposed solutions. One important factor to be considered in this phase is to ensure that those who are involved are open-minded people who give honest reviews and comments, as well as implementing the decisions made at the group meetings (Figure 12).

\subsubsection{Clash documentation}

Once the discussions have concluded, the information manager or BIM coordinator would document all the conflicts or issues,

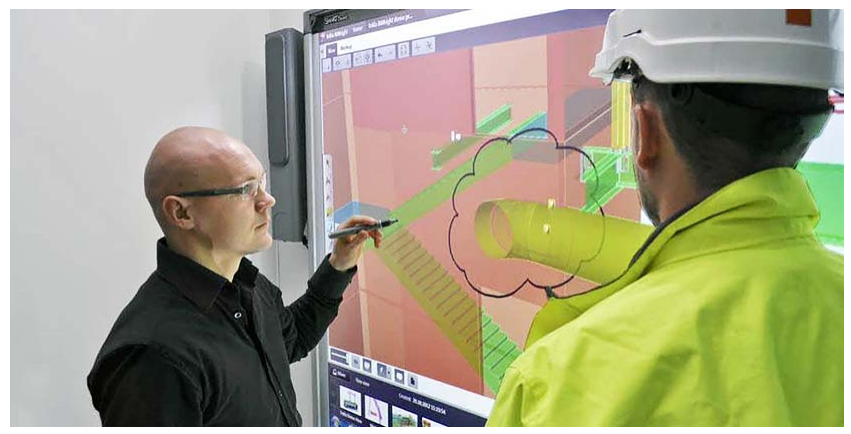

Figure 12. Boosting the project collaboration through 3D BIM models (source: Trimble) 
Smart Infrastructure and Construction

Volume 172 Issue 2
The application of clash-detection processes in building information

modelling for rebars

Chidambaram including decisions that had been made. According to the documentation strategy, they will record details of the issues to be resolved and who is accountable for implementing the recommendations. They will detail each design issue separately and prepare them for any subsequent issue identification stage. The clash reports or documents can be used as an audit trail for quality assurance and management processes (Lin and Huang, 2019).

When prefabricated reinforcement cages, meshes or roll mats are used for reinforcement in the structure, there will not be any opportunity to de-clash the reinforcing bars on-site. The declashing strategy needs to be based on the reinforcement methods of the construction (Figure 13).

Generally, rebar needs to be clash-checked against the following objects:

- rebar (Rbr)

couplers $(\mathrm{Cplr})$
- structural items (Str)

- door frames

- anchor bolts

- structural steel objects

- embedment items (Ebd)

- anchor plates

- anchor channels

- MEP items

pipes/sleeves

- earthing terminals.

It is always best to use the effective diameter for performing clashes, since it is slightly higher than the nominal diameter, due to the presence of the ribs. Rebar tolerance can be set to $3 \mathrm{~mm}$ since this is commonly used across different projects and allows

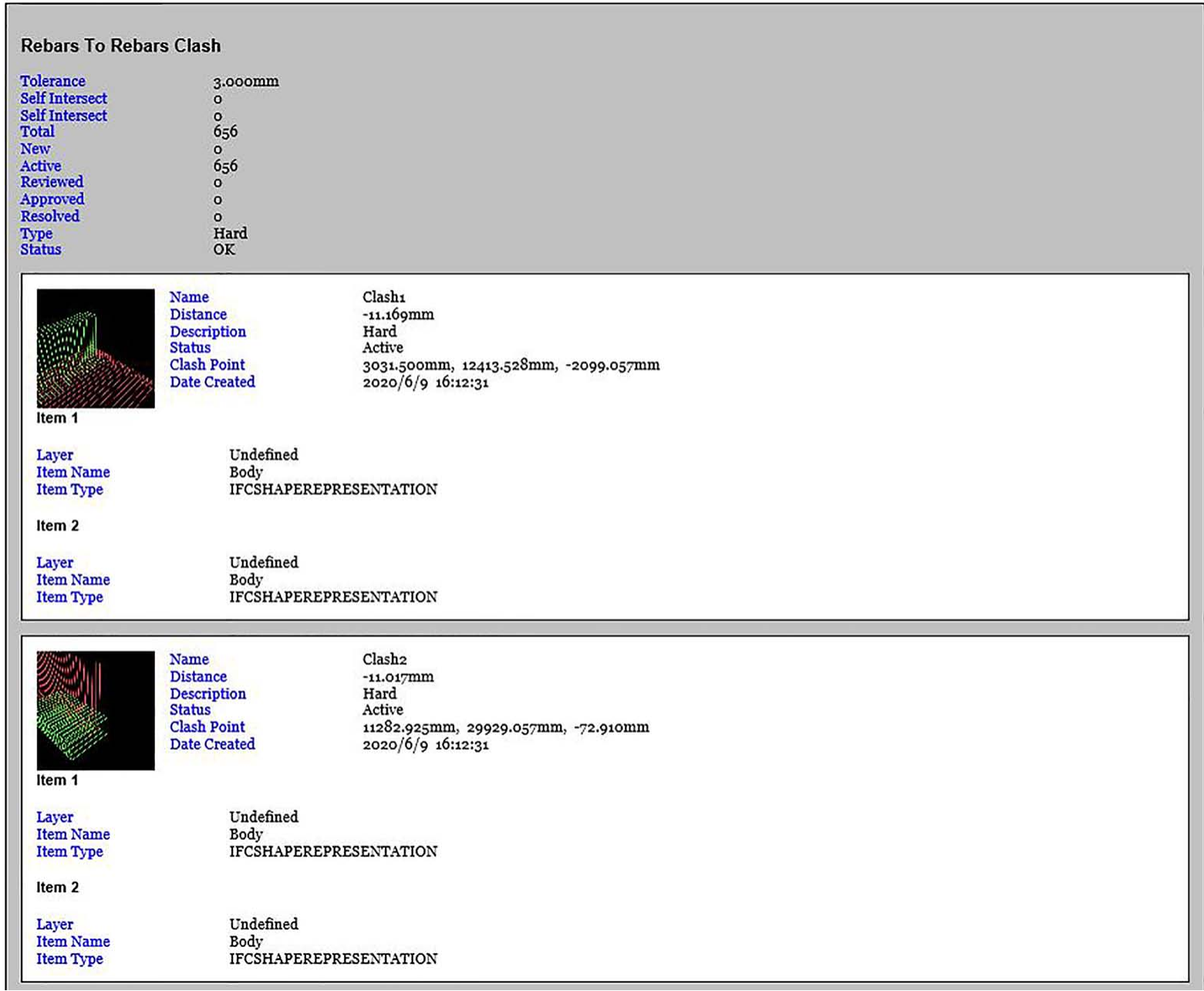

Figure 13. Rebar clash report (snapshot is taken from an example of a model in Navisworks) 
for $3 \mathrm{~mm}$ overlaps between rebar without the BIM software reporting tolerable clashes.

Rebar-to-rebar clashes should also be performed within a model or with adjacent or neighbouring models, because they may severely affect the interface between models. Great efforts are needed to resolve any interface issues between reinforcing bars in different models. Essentially, they need the alignment of coupler bars and lapping bars to form the appropriate connection between the models.

When there are changes in any discipline model, all clashes pertaining to this model must be performed again. This will highlight the impact of any changes made and any fresh clashes that made occur as a result. The updated 3D BIM can then be shared with all project stakeholders promptly. This process should be repeated until all clashes are resolved by the relevant stakeholders in each of their disciplines. Ideally, the final result should not contain any clashes between the objects within or between different discipline models.

\subsection{Clash matrix}

The clash matrix supports the user in viewing the entire list of clashes in different discipline models in a $3 \mathrm{D}$ space and drill down to clashing objects. It also provides maps of all the objects that need to be considered for the clash checks in BIM rebar models along with their tolerances.

These clash checks need to be performed with the BIM authoring or BIM integration software to identify the clashes in the model. The purpose of this is to expedite coordination efforts and avoid delays during the construction process. It is possible to perform a clash check with everything, but it also provides thousands of clashes that are not useful for project planning. By categorising the clash results into groups, it makes it much easier to coordinate and prioritise the planned solutions. Organising the information in this way allows for significant time and cost savings throughout the planning stage.

A clash-check matrix along with the tolerance values for digital reinforcement models are shown in Figure 14. The green- and redcoloured cells in the table indicate the sets that need to be included and excluded for performing clash checks, respectively (Figure 14).

\begin{tabular}{|l|c|c|c|c|c} 
& Rbr & Cplr & Str & Ebd & MEP \\
\hline Rbr & $3 \mathrm{~mm}$ & $2 \mathrm{~mm}$ & $0 \mathrm{~mm}$ & $0 \mathrm{~mm}$ & $0 \mathrm{~mm}$ \\
\hline Cplr & & $0 \mathrm{~mm}$ & $0 \mathrm{~mm}$ & $0 \mathrm{~mm}$ & $0 \mathrm{~mm}$ \\
\hline Str & & & & $0 \mathrm{~mm}$ & \\
\hline Ebd & & & & & \\
\hline MEP & & & & & \\
\hline
\end{tabular}

Figure 14. Clash-check matrix for the BIM rebar models along with tolerance values (devised by the author based on the literature)

\section{Efficiency calculation (P-T-C analysis)}

In this study, a simple formula has been created to compare manual and BIM-based clash detection. When applied, the results can compare the efficiency of one clash-detection system with that of another. This formula is based on three coefficients: performance $(P)$, preparation $(T)$ and errors $(C)$. The coefficients are calculated on the basis of comparing the reference clash detection (reference system) with the actual clash detection that needs to be assessed (examined system). The comparison of the manual and software-based systems must be based on an identical task (Matejka and Sabart, 2018).

The formula is $\eta_{\mathrm{r}}=P \times T / C$, which consists of:

- $\eta_{\mathrm{r}}-$ the relative detection efficiency, in per cent

- $P$ - the performance coefficient

- $T$ - the preparation coefficient

- $C$ - the error coefficient.

The time that it takes to detect and analyse clashes is considered in the performance coefficient. The idea is to differentiate between human and software factors because there can be significant differences in the issues identified.

The performance coefficient formula is $P=P_{\mathrm{R}} / P_{\mathrm{E}}$, which consists of:

- $P$ - the performance coefficient

- $P_{\mathrm{R}}$ - the time necessary for detection of clashes in the reference system, in seconds

- $P_{\mathrm{E}}$ - the time necessary for detection of defined clashes in the examined system, in seconds.

Where a software application is used to detect clashes, it can produce results very quickly. However, more time is required to analyse the results because the software may identify false positives or results that can be ignored for various reasons. This efficiency of specific software can be calculated using the formula $P_{\mathrm{S}}=t_{\mathrm{d}}+t_{\mathrm{c}}$, which consists of:

- $P_{\mathrm{S}}$ - the software performance coefficient (either $P_{\mathrm{E}}$ or $P_{\mathrm{R}}$ )

- $t_{\mathrm{d}}$ - the time used for computational clash-detection analysis, in seconds

- $t_{\mathrm{c}}$ - the time used for further clash analysis (result examination), in seconds.

This means that when two software applications are considered for the reference system, it is not safe to assume that $P_{\mathrm{S}}$ will be the same, even though the time that they require to detect clashes is typically very similar. The preparation time for the task in different software systems is affected by external factors and may need to be normalised - for example, how intuitive are the tools in identifying and grouping identical clashes detected from different clash sets.

The preparation coefficient formula is $T=T_{\mathrm{R}} / T_{\mathrm{E}}$, which consists of: 
T- the preparation coefficient

- $T_{\mathrm{R}}$ - the time necessary for the preparation of the reference system, in seconds

n $T_{\mathrm{E}}$ - the time necessary for the preparation of the examined system, in seconds.

The preparation coefficient should include the time required for preparation of the clash-detection rules. This way it can be used for direct comparison of approaches by addressing their user environment and set-up of the clash-detection engine.

The error coefficient provides a comparison between the clashes that have been found and existing clashes in the design using the formula $C=C_{\mathrm{R}} / C_{\mathrm{E}}$, which consists of:

- $C$ - the error coefficient

- $C_{\mathrm{R}}$ - the number of clashes found in the reference system

- $C_{\mathrm{E}}$ - the number of clashes found in the examined system.

When comparing the results for a particular task obtained by manual methods against those by software, it is strongly advised to calculate the $C_{\mathrm{E}}$ across an average of at least 20 individuals to ensure that the results are accurate. This will allow the consideration of the experience of the human analysts and their expertise in clash detection.

\section{A practical example}

In this paper, a practical example of using the $P-T-C$ analysis is shared to compare the efficiency of BIM-based clash detection against a manual analysis of the same tasks. For this purpose, a 3D BIM model with rebar was created representing a constructed reinforced concrete raft slab in an industrial building. This example was chosen because it consists of a large number of rebar, pipes in sump locations and anchor plates in the raft.

In the first phase, data were collected by looking through the drawings and reports of the existing project to obtain an understanding of its geometric description and structural materials. The key input data used in this practical example are:

- length of raft $=36 \mathrm{~m}$

nidth of raft $=30 \mathrm{~m}$

a depth of raft $=1 \mathrm{~m}$

number of sump $=1$

n number of core pit $=1$

number of plinth $=1$

concrete grade $=\mathrm{C} 40 / \mathrm{C} 50$.

The reinforcement input data used in this practical example are:

raft reinforcement

vrimary top and bottom (T1 and B1 layers) - C25 at 200 centres
- secondary top and bottom (T2 and B2 layers) - C25 at 200 centres

- shear reinforcement $-\mathrm{C} 16$ at 200 centres

- cover $-60 \mathrm{~mm}$

- column reinforcement

- $\mathrm{C} 01-500 \times 500-16$ number $\mathrm{C} 20$

- $\mathrm{C} 02-600 \times 600-16$ number $\mathrm{C} 25$

- $\mathrm{C} 03-750 \times 750-20$ number $\mathrm{C} 25$

- links $-\mathrm{C} 12$ at $200 \mathrm{~mm}$ centres

cover $-50 \mathrm{~mm}$.

The input data for this study were shared with two teams, one team (team B) carrying out clash detection using a BIM softwarebased approach and the second (team A) using a manual approach to the analysis. Each team included an RC detailing expert with more than 10 years' experience.

Team A used 2D drawings to identify the rebar-to-rebar clashes and rebar clashes with other discipline objects through cover values and sections. Using 2D RC detailing software, it took approximately 8 days $/ 72 \mathrm{~h}$ to originate four drawings to represent the raft slab with reinforcement de-clashed with other discipline objects.

Team B used 3D BIM software to develop a data-rich model and used it for clash detection. The Tekla Structures 2016i software was used to develop the 3D concrete model, adding the rebar, laps and couplers, adding user-defined attributes and exporting the results as IFC files. The modelling of pipe components and anchor plates was also carried out using the structural components in the Tekla Structures 2016i software. Experienced BIM experts were deployed to develop the concrete and rebar BIM model using the Tekla Structures software. The links, hairpins and any other construction bars that are less than or equal to $12 \mathrm{~mm}$ diameter have not been modelled, since they are not considered for clash checking. It took around 5 days $/ 45 \mathrm{~h}$ to complete the origination of the BIM rebar model containing pipes and anchor plates but not including de-clashing. Moreover, it is expected that the model will require another 2-3 days for modelling links and de-clashing the rebar. Hence, it can be safely assumed that the times required for producing $2 \mathrm{D}$ drawings and $3 \mathrm{D}$ models of the raft were almost the same (Figures 15 and 16).

The Navisworks 2016 software was used to create a federated model by combining structural and pipe models; clashes were detected by defining the clash sets and labelling the clashes by grouping them based on their nature. In this example, 3D BIM models were used in collaboration meetings to identify and discuss the clashes. The clashes are documented using either an HTML or an XLS format (Figure 17).

During the software tests, the time it took the software to process the data and identify the clashes was measured. The total number 


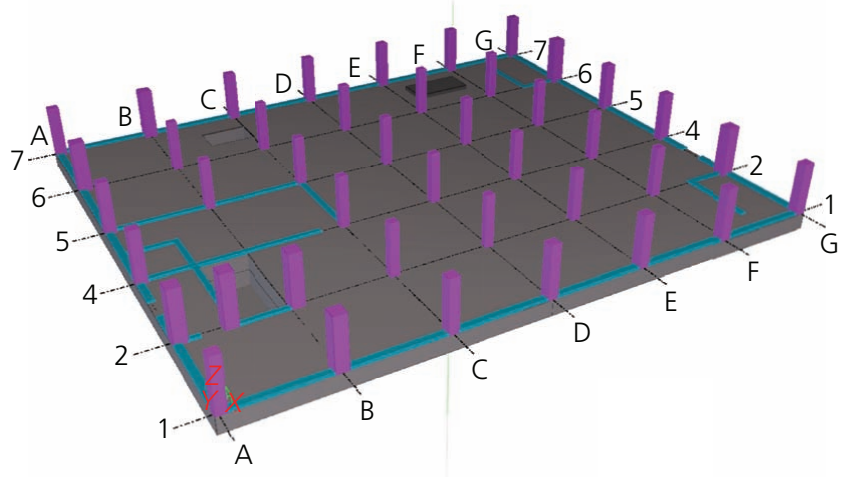

Figure 15. Concrete model of the raft slab (developed by BIM experts as a practical example)

of clashes was established to be 692 (Table 1) and used as a reference moving forward. The same process was undertaken by experts, who identified 52 'real' clashes over $2.5 \mathrm{~h}$. This time frame was based on practical observations of experts before the experiment had begun. The same group of experts was then given additional time to review and assess the results and identified a total of 71 clashes of legitimate concerns. The efficiency was then calculated using the $P-T-C$ analysis mentioned earlier, and the results are given in Table 2 .

It can be clearly seen in the results that software clash detection is far more efficient than expert human analysis. Giving the expert team more time did not significantly improve their efficiency. Although an additional 19 clashes were discovered, this still accounted for approximately $10.26 \%$ only of the total clashes found

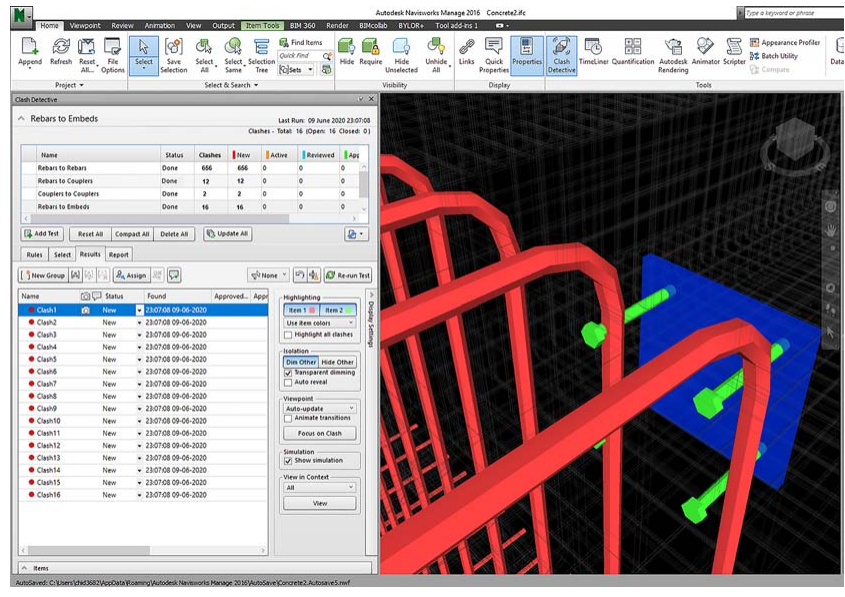

Figure 17. BIM-based clash results of the raft slab (developed by BIM experts as a practical example)

by the software in a much quicker time frame. There is probably a limit to how many clashes are even identifiable by experts.

\section{Benefits and limitations of BIM-based clash detection}

\subsection{Benefits of BIM-based clash detection}

Clash detection is a vital constituent part of BIM and crucial for the successful collaboration of multiple disciplines involved in a construction project. The clashes detected by these applications include design errors, modelling errors, coordination errors and spatial inconsistencies. The clash-detection process checks the models from all disciplines against each other for interferences. Moreover, it allows the designers to produce a highly coordinated

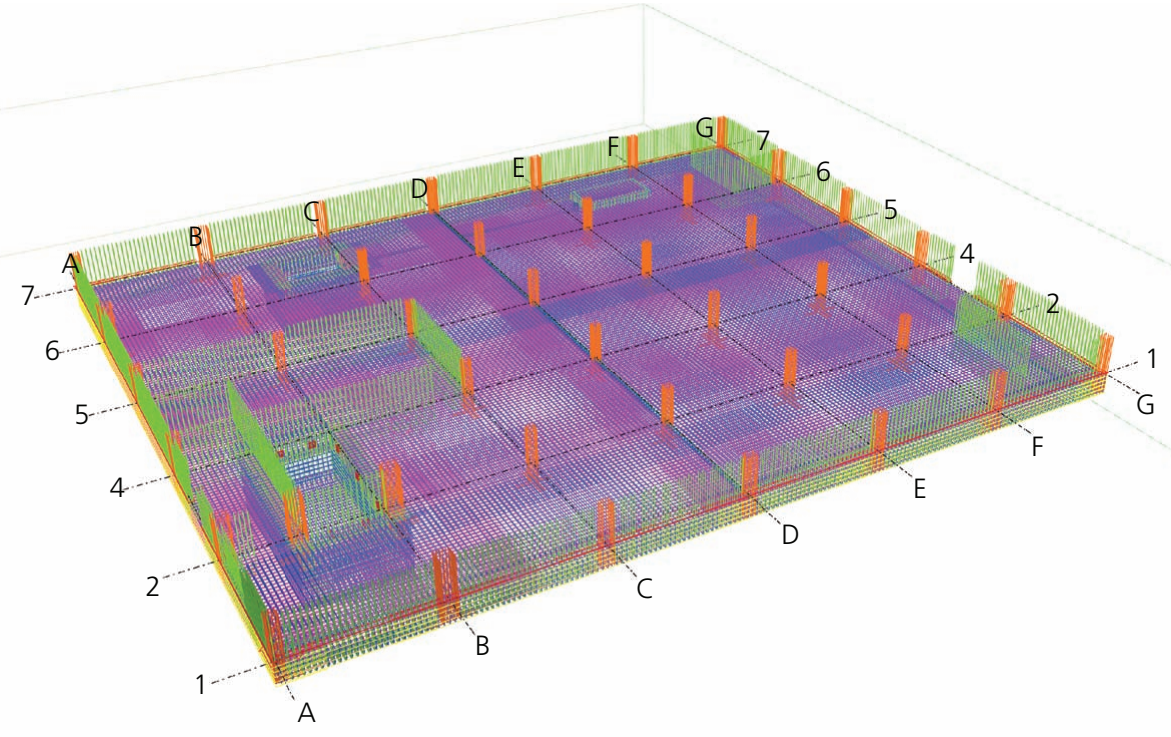

Figure 16. BIM rebar model of the raft slab (developed by BIM experts as a practical example) 
Table 1. Comparison of clash-detection results by the manual method against those the by software

\begin{tabular}{|c|c|c|c|c|c|}
\hline Variable & $\mathrm{Rbr}$ to $\mathrm{Rbr}$ & Rbr to Cplr & Cplr to Cplr & Rbr to Ebd & Rbr to MEP \\
\hline Reference system (software) & 656 & 12 & 2 & 16 & 4 \\
\hline Examined system (human) & 48 & 0 & 0 & 2 & 2 \\
\hline Examined system (human, more time) & 17 & 0 & 0 & 1 & 1 \\
\hline
\end{tabular}

Table 2. $P-T-C$ practical application

$\begin{array}{lrrrr}\text { Variable } & \boldsymbol{P} & \boldsymbol{T} & \boldsymbol{C} & \text { Efficiency: \% } \\ \text { Reference system (software) } & 14400 & 1800 & 692 & 100.00 \\ \text { Examined system (human) } & 9000 & 1800 & 52 & 12.02 \\ \text { Examined system (human, more time) } & 14400 & 1800 & 71 & 10.26\end{array}$

design that would help the site team use the highly buildable design information. As the clash detection and resolution process happens before construction, it improves the productivity of the design and construction phases of the project. However, it is essential to have high levels of collaboration between project stakeholders to achieve the significant savings that BIM-based clash detection can offer. This process addresses all of the coordination issues between different disciplines in the design stage and helps designers deliver more robust designs.

The return on investment (ROI) that BIM offers depends on various factors such as the type of project, complexity, scope and the appropriate implementation of BIM. The ROI of clash detection is a key benefit to adopting a BIM-based analysis, but it is not limited to clash detection only. The prediction of serious issues and major clashes during the design stage using BIM-based processes can reduce the change orders, technical queries, requests for information and rework, as it is expensive to address these issues at the site during the construction stage. The actual ROI achieved by a BIM methodology is also greatly improved by other benefits such as highly coordinated drawings and reports, accurate material quantities and instant updates of drawings and reports as and when there is a change in the model. The clashdetection capabilities of a BIM-based approach justify its investment without taking into consideration all the other benefits that it provides.

The BIM-based clash-detection process is highly advantageous to discover the following errors in the 3D model:
- spacing issues
a cover issues
- buildability issues
- bar length issues
- shape code issues
n coordination or interface issues.

This new approach allows designers to include the spatial requirements of other discipline objects bars and their systems in the design process so that rebar and other discipline objects are well coordinated with each other. As a result of this integration in the early design, it achieves significant time and money efficiency improvements to the project.

The poor coordination among different trades and processes and frequent design changes and/or errors are viewed as two of the major causes of production shortcomings in the preinstallation stage. Many researchers proposed that coordination meetings during the design stage are more effective than addressing the clashes during the later stages.

\subsection{Benefits of BIM-based clash detection from the global literature}

Low productivity has been a constant issue in the construction industry, including steel fixing and placing. This low productivity raises costs and adds risk and waste across project life cycles. Productivity is a very relevant topic right now.

Clash detection helps in reducing the coordination errors and differences of opinion between the personalities of different disciplines. Clash detection ensures better coordination of rebar with other discipline objects to deliver improved outcomes. The clash-detection and resolution processes on any construction project would lead to the potential benefit of saving up to $10 \%$ of the contract value, and approximately $1 \%$ of the contract value is attributable to rebar by considering that the average cost of reinforcement is $10 \%$ of the total project cost (CRCCI, 2007).

Three-dimensional BIM facilitates clash detection and incorporates programme details, cost constraints and assetmanagement information; it optimises the use of data throughout the project life cycle without loss, contradiction or misinterpretation. By learning from these experiences and implementing solutions adeptly across the full life cycle of a project, Atkins can achieve as much as a $20 \%$ reduction in the time needed for completing a project and up to $16 \%$ in cost savings only in the design phase (WEF, 2016).

The Economist Intelligence Unit Survey says that $36 \%$ of the respondents acknowledged that virtual design and construction or BIM have had the greatest impact on improving the productivity in the construction sector (EIU, 2015). 
Many companies focus on the future, mainly because they want to reduce the labour cost on-site, which is the most expensive part of the reinforcement process in global terms. Concrete materials make up approximately $18 \%$ of the total cost of a project, the labour on concrete totals about $5 \%$ to $6 \%$, while the formwork materials make up about $6 \%$ of costs. The balance of reinforcement supply, prefabrication and reinforcement labour costs are equally spread at around $9 \%$.

Labour-intensive processes, such as formwork and reinforcement, can be addressed, planned and subsequently improved using clashresolved 3D reinforcement models created in the BIM software. In addition, the 3D model reduces the likelihood of unforeseen errors on-site, preventing the requirement for additional labour to rectify the mistakes (Trimble Solutions, 2016).

\subsection{Limitations of BIM-based clash detection}

This new approach is best suited to large projects that require collaboration between different disciplines. This approach can be adopted in any type of project, but its benefits will vary.

It is impractical to de-clash all the rebar in the structure of a 3D model since it is a time-consuming process. There should be a clear distinction in the BIM execution plan about which bars need to be de-clashed and which bars should be excluded to ensure the high buildability of digital reinforcement models. For example, links, hairpins and any other bars that are less than or equal to $12 \mathrm{~mm}$ need not be considered widely for clash detection since they can be easily de-clashed at the site.

BIM-based clash detection for rebar requires more computing power and higher-powered computer systems than traditional computer-aided drafting work, and this comes with a cost.

The proposed $P-T-C$ analysis was applied to a practical example to demonstrate the benefits of BIM-based clash detection for rebar. Although the presented examples are not statistically relevant (more tests should be conducted with different variables and project types), they demonstrate the simplicity and possible use of $P-T-C$ analysis.

\section{Use of clash-resolved BIM models by construction professionals}

The outcome of the clash detection and resolution process is a clash-resolved BIM model with rebar. It is very important to communicate this valuable information - that is, the de-clashed position of every single rebar - to the construction team so that they adhere to the de-clashed position instead of nominal design spacing, to increase the productivity of the rebar processes. The de-clashed position of rebar or other elements such as anchor plates, anchor channels and pipes can be communicated to the site through 3D models. The construction team can access all the information that is required for construction from 3D models. These data-rich models would be highly beneficial during the rebar procurement, fabrication and placing/fixing processes.

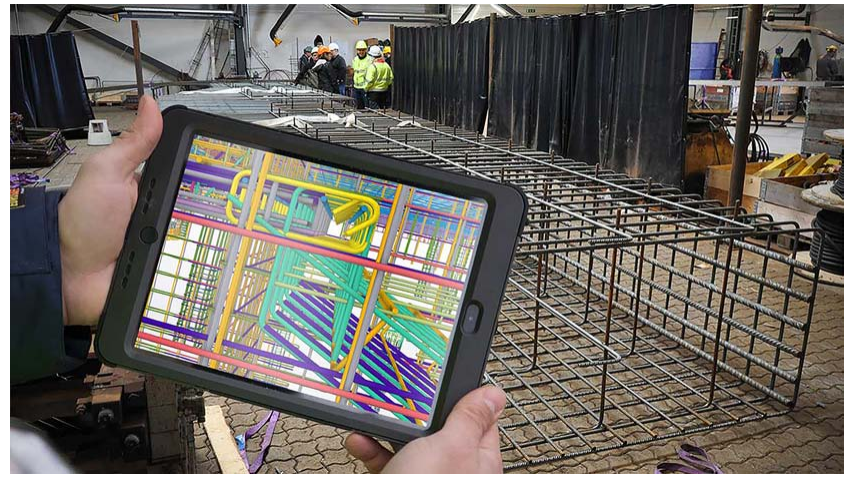

Figure 18. Use of clash-resolved BIM models by construction professionals through iPads, tablets and mobile phones (source: Trimble)

Three-dimensional BIM rebar models may be centrally held in the project office or the cloud so that they could be accessed directly using iPads or similar electronic devices (Figure 18).

\section{Conclusion}

The objective of this paper was to explore the benefits of using a BIM-based process for clash detection among rebar. For that purpose, a literature review of the information about clash detection and BIM has been done.

Many researchers have stated that it is far more cost and time effective to eliminate clashes in the early design stages rather than addressing them during the construction phase of the project. By using a BIM-based approach, one can eliminate reworking in reinforcing steel works as any design faults can be addressed before construction even begins. The practice of including rebar in the 3D BIM model clash-detection process has been detailed in this paper.

An attempt has been made to compare the current method of resolving rebar clashes on-site and the BIM-based clash-detection process using an example of a $P-T-C$ analysis. The case study is not statistically relevant; it has been conducted to demonstrate the use of a simple formula.

Furthermore, it appears that using a BIM-based clash-detection process would uncover clashes and provide an opportunity for designers to resolve them earlier in the design process. As a result, it would increase the cost-effectiveness of using rebar in the construction plans.

\section{REFERENCES}

Allplan (2018) Why use BIM for reinforced concrete modelling? The Allplan Blog, 5 December. See https://blog.allplan.com/en/reinforcedconcrete-modeling (accessed 10/06/2020).

Anderson OA and Zulfikar AA (2017) Clash detection or clash avoidance? An investigation into coordination problems in 3D BIM. Buildings

7(3): article 75, https://doi.org/10.3390/buildings7030075. 
Benning P, Dumoulin C, Dehlin S et al. (2010) Report on collaboration processes. In Framework for Collaboration. InPro Consortium, Brussels, Belgium, pp. 100-125.

BIM@SG (2012) What are BIM tools? BIM@SG, 4 January. See https:// bimsg.org/2012/01/04/what-is-bim-authoring-tools/ (accessed 10/06/ 2020).

Cherkaoui H (2016) What is BIM? What are its benefits to the construction industry? LetsBuild Blog, 1 December. See https://www. letsbuild.com/blog/what-is-bim-what-are-its-benefits-to-theconstruction-industry (accessed 10/06/2020).

CRCCI (Cooperative Research Center for Construction Innovation) (2007) Adopting BIM for Facilities Management: Solutions for Managing the Sydney Opera House. CRCCI, Brisbane, Australia.

Eastman C, Eastman CM, Teicholz P and Sacks R (2011) BIM Handbook: a Guide to Building Information Modelling for Owners, Managers, Designers, Engineers and Contractors, 2nd edn. Wiley Hoboken, NJ, USA.

EIU (The Economist Intelligence Unit) (2015) Rethinking Productivity across the Construction Industry. EIU, London, UK.

Forsythe PF (2014) The productivity of steel reinforcement placement in Australian construction. In Proceedings of the International Cost Engineering Council (ICEC) IX World Congress, Milan, Italy, pp. 1-9.

Ghanem AA and Wilson N (2011) Building information modelling applied on a major CSU capital project: a success story. Proceedings of the 47th ASC Annual International Conference, Omaha, NE, USA, pp. 1-8.

Illingworth JR (2000) Construction Methods and Planning, 2nd edn. E\&FN Spon London, UK.

Lin WY and Huang YH (2019) Filtering of irrelevant clashes detected by BIM software using a hybrid method of rule-based reasoning and supervised machine learning. Applied Sciences 9(24): article 5324, https://doi.org/10.3390/app9245324.

Matejka P and Sabart D (2018) Categorization of clashes and their impacts on construction projects. Proceedings of the 17th
International Scientific Conference 'Engineering for Rural Development, Jelgava, Latvia, pp. 827-835.

McKinsey (2016) Imagining Construction's Digital Future. McKinsey, New York, NY, USA.

NBS (National Building Specification) (2019) What Is Building Information Modelling? NBS, Newcastle upon Tyne, UK. See https:// www.thenbs.com/knowledge/what-is-building-information-modellingbim (accessed 10/06/2020).

NIBS (National Institute of Building Sciences) (2019) About the National BIM Standard-United States ${ }^{\circledR}$. NIBS, Washington, DC, USA. See https://www.nationalbimstandard.org/about (accessed 10/06/2020).

Nour M and Beucke K (2010) Object versioning as a basis for design change management within a BIM context. In Proceedings of the International Conference on Computing in Civil and Building Engineering (Tizani W (ed.)). Nottingham University Press, Nottingham, UK, pp. 147.

Trimble Solutions (2016) Tekla Software in Practice: Midland Steel Reinforcement Supplies. Trimble Solutions Corp., Espoo, Finland. See http://pages.tekla.com/rs/093-TQY-221/images/UK16-Midland-steel. pdf (accessed 10/06/2020).

Trimble Solutions (UK) Ltd (2020) Your Checklist for Choosing Your Building Information Modelling Solutions. Trimble Solutions (UK) Ltd, Leeds, UK. See https://www.tekla.com/uk/6-things-considerwhen-buying-bim-software (accessed 10/06/2020).

Veillette C (2016) Understanding clash detection and making it more efficient. BIM Track Blog, 28 July. See https://bimtrack.co/blog/blogposts/understanding-clash-detection-and-making-it-more-efficient (accessed 10/06/2020).

WEF (World Economic Forum) (2016) Shaping the Future of Construction - a Breakthrough in Mindset and Technology. WEF, Cologny, Switzerland. See http://www3.weforum.org/docs/ WEF_Shaping_the_Future_of_Construction_full_report_.pdf (accessed on 10/06/2020)

\section{How can you contribute?}

To discuss this paper, please email up to 500 words to the editor at journals@ice.org.uk. Your contribution will be forwarded to the author(s) for a reply and, if considered appropriate by the editorial board, it will be published as discussion in a future issue of the journal.

Proceedings journals rely entirely on contributions from the civil engineering profession (and allied disciplines). Information about how to submit your paper online is available at www.icevirtuallibrary.com/page/authors, where you will also find detailed author guidelines. 